\title{
Evaluation of Serum 25-Hydroxyvitamin Vitamin D, Vitamin B12, and Folate Levels in Patients with Benign Paroxysmal Positional Vertigo
}

\author{
(1) Hamit Çelik¹, (1) Ahmet Yardım², (1) Atilla Ertaș ${ }^{3}$, (1) Behçet Varıșlı4, (1) Özgül Ocak \\ ${ }^{1}$ Clinic of Neurology, Private Buhara Hospital, Erzurum, Turkey \\ ${ }^{2}$ Clinic of Neurosurgery, Private Buhara Hospital, Erzurum, Turkey \\ ${ }^{3}$ Clinic of Otorhinolaryngology, Private Buhara Hospital, Erzurum, Turkey \\ ${ }^{4}$ Clinic of Emergency Department, Çanakkale State Hospital, Çanakkale, Turkey \\ ${ }^{5}$ Department of Neurology, Çanakkale Onsekiz Mart University Faculty of Medicine, Çanakkale, Turkey
}

\begin{abstract}
Aim: This study aimed to compare 25-hydroxyvitamin D (25-OH Vit D), vitamin B12, and folic acid levels in patients presenting with vertigo diagnosed with benign paroxysmal positional vertigo (BPPV) and healthy volunteer control group without vertigo, and to examine whether they are disease-associated.

Materials and Methods: A total of 190 patients who applied between October to December 2019 diagnosed with BPPV and 149 volunteers without any complaints (control group), who came only for checkup, were included in the study. Serum 25-OH Vit D, vitamin B12, and folic acid levels of all participants were examined.

Results: Of all participants, 209 (61.6\%) were male and 130 (38.4\%) were female. Out of 94 participants, 25-OH Vit D level was found to be at low levels. Of participants with low 25-OH Vit D levels, 65 (69.1\%) were in the BPPV group and 29 (30.9\%) were in the control group. Of all participants, 68 had low folic acid levels, wherein 33 (48.5\%) were in the control group and 35 (51.5\%) were in the BPPV group. The level of vitamin B12 of 2 participants among all participants was below normal values and these 2 participants were in the BPPV group.

Conclusion: In our study, any significant relationship was not found between BPPV and serum vitamin B12 and serum folic acid levels. A significant relationship was determined between BPPV and decreased serum 25-OH Vit D level $(p<0.01)$. We identified that low serum 25-OH Vit D levels may be an independent risk factor in the progress of BPPV.
\end{abstract}

Keywords: Vertigo, benign paroxysmal positional vertigo, 25-OH vitamin D, vitamin B12, folic acid

\section{Introduction}

Benign paroxysmal positional vertigo (BPPV) is the most common disease among peripheral vestibular diseases. BPPV, being the most common cause of vertigo in adults (1). BPPV occurs when the otoconia (otolith) breaks away from the utricular or saccular (vestibular end organs) macula, falls into one of the semicircular canals (canalithiasis) or attachesonto the cupula (cupulolithiasis). Clinical complaints occur when the otoconia's sensitivity to gravity increases (2). Cupulolithiasis and canalithiasis are two important mechanisms implicated in the development of BPPV disease. Canalithiasis is responsible for $80 \%$ of the cases (3). BPPV is a common disease and its lifetime prevalence is $2.4 \%$ (4). The main component of the otolith crystals is calcium carbonate and glycoprotein and these otoconia crystals attach to the hairy cells in the vestibule by protein bonds. It has been proven in studies that the otoconia crystals are the active calcium metabolite of the utricle and the saccule (5-8).

Rat studies have proven that vitamin D dependent calcium channel proteins play a role in active calcium metabolism of vestibular saccule and utricle (9-11). 
Many studies have demonstrated that decrease in bone density, osteopenia and osteoporosis are associated with BPPV. Those studies compared BPPV patients with control groups in terms of 25-Hydroxyvitamin Vitamin D (25-OH Vit D) levels and showed that BPPV patients had lower 25-OH Vit D levels compared to control groups $(10,12,13)$.

Some studies reported both BPPV development and BPPV recurrence to be associated with 25-OH Vit D deficiency. BPPV recurrence is common. BPPV repeats in one of every five cases which occurred in one year, and in one of two cases which occurred in 5 years (14).

Right posterior canal is the most commonly involved canal in BPPV and in 70\% of the patient's unilateral involvement is the case (13). Involvement of the right side is attributed to the by the habit of lying on the right side the most. 85-90\% of all BPPVs are composed of posterior canal BPPVs, 5-15\% are horizontal canal BPPVs and less than 5\% are anterior canal BPPVs (15).

Although the etiology of BPPV is not clear, some studies suggest that factors such as internal ear diseases, hormonal factors, female sex, viral diseases, migraine, head and neck traumas, senior age and family history are predisposing in disease formation (16-18).

The prevalence of BPPV in women is explained by the fact that migraine is more common in women and increased BPPV relationship in migraineurs (19).

BPPV carries the word "benign" in its name because vertigo is peripheral and can be treated successfully. It would be wrong to discontinue treatment considering that there would be spontaneous remission. There are studies suggesting that BPPV negatively affects daily life, increases the risk of falling and the frequency of depression, especially in the elderly and recurrent cases $(16,20,21)$.

Clinical studies and rat studies indicate that the calcium metabolism in BPPV patients may be disrupted due to low 25$\mathrm{OH}$ Vit D level (9-13).

In the literature, there are publications pointing out that low vitamin B12 level is associated with the development of BPPV, however there are also studies suggesting otherwise $(22,23)$.

In addition, studies examining the relationship between peripheral vertigo and B12 have found a correlation between low level of vitamin B12 and development of vertigo $(24,25)$.

There are studies investigating the relationship between folic acid level and vertigo, however no studies examining the relationship between folate and BPPV exist in the literature (26).
In this study we aimed to compare 25-OH Vit D, vitamin B12 and folic acid levels between BPPV patients and control group and to investigate the relationship of BPPV with the mentioned substances.

\section{Materials and Methods}

Consent of all patients and volunteers included in the study was obtained. We included in the patient group a total of 190 patients (120 males and 70 females) who presented to the outpatient clinics of neurology, otorhinolaryngology, emergency and neurosurgery with the complaint of dizziness and were diagnosed with BPPV in October and November 2019. Otorhinolaryngology specialist performed the Dix-Hallpike maneuver on all the patients who suffered from dizziness. We observed the side, direction, duration and fatigue characteristics of the cases which we determined to have nystagmus and we applied lateral canal test to those without nystagmus. We performed repositioning for canalithiasis and releasing maneuvers for cupulolithiasis for the treatment of patients diagnosed with BPPV. We controlled the patients again within 2-3 days periods and applied the requisite maneuvers as required. Dix-Hallpike and lateral canal tests were performed until nystagmus disappeared.

The control group was composed of 149 healthy volunteers (89 males and 60 females) who presented to the hospital for checkup and who did not receive $25-\mathrm{OH}$ Vit D, B12 and folic acid supplements, had not previously been diagnosed with BPPV, had no complaints of dizziness within the past year, and had no history of trauma in the last 7 days. We performed neurological examination to the entire patient group. We excluded those with pathological findings in neurological examinations, who had unexpected hearing loss in audiometric examination, who had other peripheral or central vertigo other than BPPV, patients who had internal ear surgery, head trauma surgery, drug-induced ototoxicity, dizziness due to drug discontinuation. patients with diagnosed osteoporosis and those using B12, folate, and vitamin D replacement from the study.

\section{Measurement of 25-OH Vitamin D, Vitamin B12, Folate Levels}

25-OH Vit D, vitamin B12 and folic acid levels in the serum obtained from the morning blood samples taken from BPPV patients were measured in Mindray Perfect Plus 400 (Germany) biochemistry autoanalyzer by applying electroluminescence method.

We regarded the normal ranges of $25-\mathrm{OH}$ Vit D, vitamin B12 and folate as 10.6-43.4 ng/mL, 211-911 pg/mL, and $>5.38 \mathrm{ng} /$ $\mathrm{mL}$ respectively. We then statistically compared the data of both groups. 
The study was approved by the Ethics Committee of University of Health Sciences Turkey, Erzurum Regional Training and Research Hospital (no: 2019/12-122, date: 07.10.2019). We complied with the principles of the Declaration of Helsinki during the study.

\section{Statistical Analysis}

The difference in gender, vitamin D, vitamin B12 and folic acid levels between BPPV and control groups was made using the Mann-Whitney $U$ test, one of the non-parametric tests. We analyzed the age relationships of BPPV and control groups by two independent sample t-tests. We employed SPSS 20.0 package program for all analyses. We regarded $p<0.05$ as statistically significant.

\section{Results}

The mean age of the control group was $33.14 \pm 13.44$, while the mean age of the BPPV group was $43.68 \pm 16.04$. There was no significant difference between the age and gender variables in the control group and in the BPPV group ( $p>0.05)$ (Table 1).

The number of patients with BPPV was 190 (56\%) and the number of participants in the control group was 149 (44\%). Of the male participants included in the study, 120 (57.4\%) were in the BPPV group and 89 (42.6\%) were in the control group. Of the female participants, 60 (46.2\%) were in the control group and 70 (53.8\%) were in the BPPV group. There was no significant difference between the gender variable and the progress of BPPV $(p>0.05)$ (Table 2). Of the participants included in the study, the mean values of those with low levels of 25-OH Vit D, vitamin B12, and folic acid were $8.15 \pm 0.189(\mathrm{ng} / \mathrm{mL}), 191.00 \pm 20.00(\mathrm{pg} / \mathrm{mL})$ and $3.73 \pm 0.143(\mathrm{ng} / \mathrm{mL})$ respectively, while these values were found to be as $18.91 \pm 0.442(\mathrm{ng} / \mathrm{mL}), 457.38 \pm 7.15(\mathrm{pg} / \mathrm{mL})$ and $11.53 \pm 0.283(\mathrm{ng} / \mathrm{mL})$ respectively for those with normal values. Of 94 participants included in the study, 25-OH Vit D level was found to be at low levels. Of the participants with low $25-\mathrm{OH}$ Vit D levels, 65 (69.1\%) were in the BPPV group and 29 (30.9\%) were in the control group. 25-OH Vit D levels of 245 participants included in the study were found to be at normal values. Of those with normal levels, 120 (49\%) were in the control group and 125 (51\%) were in the BPPV group (Graphic 1). We determined that the risk of developing BPPV was higher in those with low $25-\mathrm{OH}$ Vit $\mathrm{D}(\mathrm{p}<0.01)$ (Table 3). Of all participants included in the study, 68 had low folic acid levels and 33 (48.5\%) of them were in the control group, while 35 (51.5\%) of them were in the BPPV group (Table 4). The level of vitamin B12 of two participants among all participants included in the study was below the normal values (Table 5) and these two participants were in the BPPV group. We found that there was no relationship between the low or normal levels of vitamin B12 and folic acid with the prevalence of BPPV $(p>0.05)$.

\begin{tabular}{|c|c|c|c|c|c|}
\hline Group statistics & & $n$ & Mean & SD & SE (mean) \\
\hline \multicolumn{6}{|l|}{ Age (year) } \\
\hline & Control & 149 & 33.1477 & 13.44879 & 1.10177 \\
\hline & BPPV & 190 & 43.6842 & 16.04080 & 1.16372 \\
\hline \multicolumn{6}{|c|}{$25-0 \mathrm{H}$ vitamin $\mathrm{D}(\mathrm{ng} / \mathrm{mL})$} \\
\hline & Control & 149 & 16.2928 & 6.66072 & 0.54567 \\
\hline & BPPV & 190 & 15.6357 & 8.37392 & 0.60751 \\
\hline \multicolumn{6}{|c|}{ Vitamin B12 (pg/mL) } \\
\hline & Control & 149 & 453.6779 & $132.90361 \mid$ & 10.88789 \\
\hline & BPPV & 190 & 457.4842 & 132.57082 & 9.61770 \\
\hline \multicolumn{6}{|c|}{ Folic acid (ng/mL) } \\
\hline & Control & 149 & 9.5990 & 5.17374 & 0.42385 \\
\hline & BPPV & 190 & 10.2671 & 5.28406 & 0.38335 \\
\hline
\end{tabular}

Table 2. Gender distribution of healthy and BPPV groups

\begin{tabular}{|l|l|l|l|l|}
\hline & Control & BPPV & Total & p-value \\
\hline Male & $89(42.5 \%)$ & $120(57.4 \%)$ & 209 & $p>0.05$ \\
\hline Female & $60(46.1 \%)$ & $70(53.8 \%)$ & 130 & 339 \\
\hline Total & 149 & 190 & & \\
\hline BPPV: Benign paroxysmal positional vertigo & & & \\
\hline
\end{tabular}




\begin{tabular}{|c|c|c|c|c|c|}
\hline & & Control & BPPV & Total & p-value \\
\hline 25-0H D vitamin levels & Deficiency & $29(30.9 \%)$ & 65 (69.1\%) & 94 & \multirow[t]{2}{*}{$p<0.01$} \\
\hline \multicolumn{2}{|l|}{ Total } & 149 & 190 & 339 & \\
\hline
\end{tabular}

\begin{tabular}{|c|c|c|c|c|c|}
\hline & & Control & BPPV & Total & $p$-value \\
\hline Folic acid levels & Deficiency & 33 (48.5\%) & $35(51.5 \%)$ & 68 & \multirow[t]{2}{*}{$p>0.05$} \\
\hline \multicolumn{2}{|l|}{ Total } & 149 & 190 & 339 & \\
\hline
\end{tabular}

Table 5. Relationship between vitamin B12 level and BPPV group and control group

\begin{tabular}{|l|l|l|l|l|l|}
\hline & & Control & BPPV & Total & p-value \\
\hline Vitamin B12 levels & Deficiency & $0(0 \%)$ & $2(100 \%)$ & 2 & $p>0.05$ \\
\cline { 2 - 6 } & Normal & $149(44.2 \%)$ & $188(55.8 \%)$ & 337 & 339 \\
\hline Total & 149 & 190 & \\
\hline BPPV: Benign paroxysmal positional vertigo
\end{tabular}

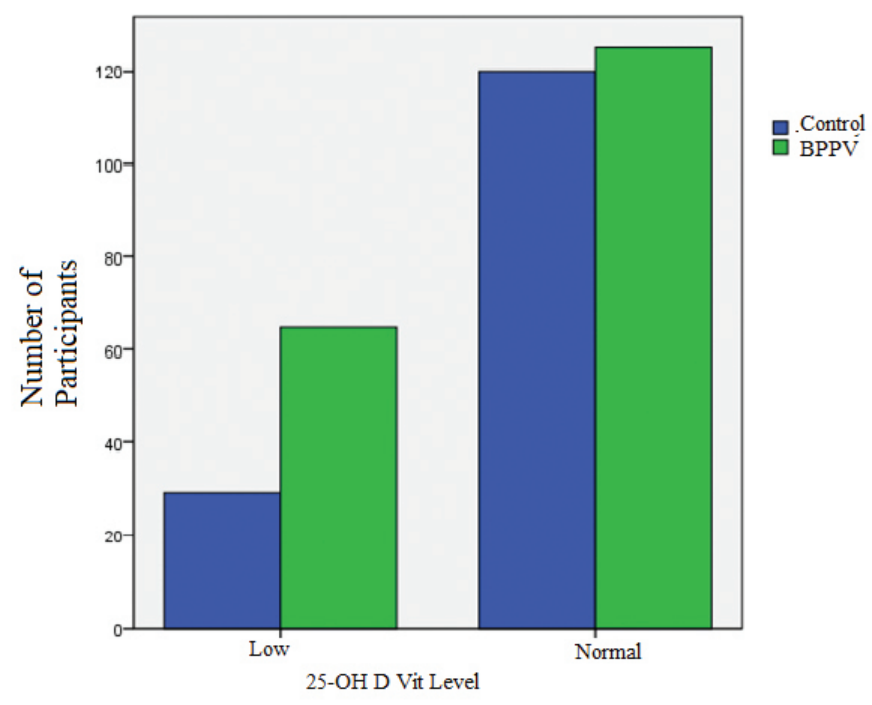

Graphic 1. 25-OH vitamin D levels of control and BPPV group BPPV: Benign paroxysmal positional vertigo

\section{Discussion}

The etiology of BPPV is explained by the fact that otoliths break away from the vestibular end organs and fall off or attach to the semicircular canal (2). Utricle and saccule are active calcium metabolites composed of calcium carbonate and glycoproteins (9). Otolith formation needs increased local calcium concentration. Studies have shown the presence of calcium channels such as Calbindine and the plasma membrane calcium pump, which play an important role in calcium absorption from the vestibular endolymph (27). In the studies on rats, it was observed that the expression of calcium-binding proteins in calcium channels in epithelial cells of semicircular canals is increased by $25-\mathrm{OH}$ Vit D (11). Xu et al. (28). found common characteristics between biomineralization of bone and otoliths. They observed that the matrix organization of both tissues had similar characteristics. Studies in the literature have shown that BPPV is more common in women with osteoporosis and osteopenia, and they have frequent recurrences $(10,12,16)$. There are also studies indicating that vitamin D replacement significantly reduces recurrence in BPPV patients $(13,14)$. In our study, we compared the serum 25-OH Vit D levels in the BPPV group and control group, and found that the serum 25-OH Vit D levels of patients with BPPV were significantly lower than the control group $(p<0.01)$. We examined the mean levels of serum 25-OH Vit D of the BPPV patients and the control group without any vestibular complaints and found these mean levels as $15.63 \pm 0.60$ and $16.29 \pm 0.54$ respectively. The mean level of $25-\mathrm{OH}$ Vit D in the BPPV group was lower than the control group. The level of decreased serum $25-\mathrm{OH}$ Vit $\mathrm{D}$ was found to be likely a risk factor independent from 
the age and gender variable for the progress of BPPV. BPPV is the most common recurrent pathogenesis of vertigo in adults, and its prevalence in the general population is 10\% (29). In another study, it was reported that $24 \%$ of patients abstain from driving their vehicles in the period of BPPV attacks and 18\% of them hesitate over going out of their houses (4). Examining the BPPV disease that is commonly seen in the general population under light of literature, the necessity of effective treatment of the disease is better understood. There were no papers investigating the relationship between serum folic acid level and BPPV in the literature. In our study, we found that the low or normal levels of serum vitamin B12 and folic acid are not a risk factor in the progress of BPPV.

\section{Conclusion}

In our study, we assume that the low levels of 25-OH Vit D are risk factors independent of age and gender in the progress of BPPV. We did not find a significant relationship between vitamin B12 and folic acid levels with the progress of BPPV. The measurement of $25-\mathrm{OH}$ Vit D levels in patients diagnosed with BPPV and administering replacement treatment may be beneficial. There is scientific evidence in the literature on the fact that replacement treatment may overcome the clinical complaints and may provide a reduction in the recurrence rate (14). Multicenter prospective studies with wider participation are needed to better understand the effect of 25-OH Vit D in BPPV and to prove the need for treatment.

\section{Ethics}

Ethics Committee Approval: The study was approved by the Ethics Committee of University of Health Sciences Turkey, Erzurum Regional Training and Research Hospital (no: 2019/12122, date: 07.10.2019).

Informed Consent: Consent of all patients and volunteers included in the study was obtained

Peer-review: Externally peer-reviewed.

\section{Authorship Contributions}

Surgical and Medical Practices: H.Ç., A.Y., A.E., Concept: H.Ç., Ö.O., Design: H.C.., A.Y., B.V., Data Collection or Processing: H.C.., A.E., Analysis or Interpretation: A.Y., A.E., B.V., Literature Search: A.Y., A.E., B.V., Ö.O., Writing: H.Ç., B.V.

Conflict of Interest: No conflict of interest was declared by the authors.

Financial Disclosure: The authors declared that this study received no financial support.

\section{References}

1. Neuhauser HK. Epidemiology of vertigo. Curr Opin Neurol. 2007;20:40-6.

2. Parnes LS, Agrawal SK, Atlas J. Diagnosis and management of benign paroxysmal positional vertigo (BPPV). CMAJ. 2003;169:681-93.

3. Baloh RW, Kerber KA. Clinical neurophysiology of the vestibular system. Oxford University Press, 4th ed. 2011.p.255-271.

4. von Brevern M, Radtke A, Lezius F, et al. Epidemiology of benign paroxysmal positional vertigo: a population based study. J Neurol Neurosurg Psychiatry. 2007;78:710-5.

5. Fife D, FitzGerald JE. Do patients with benign paroxysmal positional vertigo receive prompt treatment? Analysis of waiting times and human and financial costs associated with current practice. Int J Audiol. 2005;44:50-7.

6. Oghalai JS, Manolidis S, Barth JL, Stewart MG, Jenkins HA. Unrecognized benign paroxysmal positional vertigo in elderly patients. Otolaryngol Head Neck Surg. 2000;122:630-4.

7. Welgampola M, Bradshaw A, Halamgyi GM. Dizziness on head movement. MJA 2011;195:518-22.

8. Lundberg YW, Zhao X, Yamoah EN. Assembly of the otoconia complex to the macular sensory epithelium of the vestibule. Brain Res. 2006;1091:47-57.

9. Hoenderop JG, Nilius B, Bindels RJ. Calcium absorption across epithelia. Physiol Rev. 2005;85:373-422.

10. Yamanaka T, Shirota S, Sawai Y, Murai T, Fujita N, Hosoi H. Osteoporosis as a risk factor for the recurrence of benign paroxysmal positional vertigo. Laryngoscope 2013;123:2813-6.

11. Yamauchi D, Raveendran NN, Pondugula SR, Kampalli SB, Sanneman JD, Harbidge DG, et al. Vitamin D upregulates expression of ECaC1 mRNA in semicircular canal. Biochem Biophys Res Commun. 2005;331:1353-7.

12. Jeong SH, Choi SH, Kim JY, Koo JW, Kim Hj, Kim JS. Osteopenia and osteoporosis in idiopathic benign positional vertigo. Neurology. 2009;72:1069-76.

13. Talaat HS, Abuhadied G, Talaat AS, Abdelaal MSS. Low bone mineral density and vitamin D deficiency in patients with benign positional paroxysmal vertigo. Eur Arch Otorhinolaryngol. 2015;272:2249-53.

14. Rhim GI. Variables for one year recurrence of benign paroxysmal positional vertigo. Korean J Otorhinolaryngol-Head Neck Surg. 2014;57:314-9.

15. von Brevern M, Seelig T, Neuhasuer H, Lempert T. Benign paroxysmal positional vertigo predominantly affects the. right labyrinth. J Neurol Neurosurg Psychiatr. 2004;75:1487-8.

16. Vibert D, Häusler R. Acute peripheral vestibular deficits after whiplash injuries. Ann Otol Rhinol Laryngol. 2003;112:246-51.

17. Gizzi M, Ayyagari S, Khattar V. The familial incidence of benign paroxysmal positional vertigo. Acta Oto Laryngol. 1998;118:774-7.

18. Vibert $\mathrm{D}$, Kompis $\mathrm{M}$, Häusler R. Benign paroxysmal positional vertigo in older women may be related to osteoporosis and osteopenia. Ann Otol Rhinol Laryngol. 2003;112:885-9.

19. Ishiyama A, Jacobson KM, Baloh RW. Migraine and benign paroxysmal positional vertigo. Ann Oto Rhinol Laryngol. 2000;109:377-80.

20. Ross MD, Pote K, Rarey K, Verma L. Microdisc gel electrophoresis in sodium dodecyl sulfate of organic material from rat otoconial complexes. Ann N Y Acad Sci. 1981;374:808-19.

21. Johnsson LG, Rouse RC, Wright CG, Henry PJ, Hawkins JE. Pathology of neuroepithelial suprastructures of the human inner ear. Am J Otolaryngol. 1982;3:77-90.

22. Mahmud K, Ripley D, Doscherholmen A. Paroxysmal positional vertigo in vitamin B12 deficiency. Arch Otolaryngol. 1970;92:278-80.

23. Tekeşin A, Tunç A. Inflammatory biomarkers in benign paroxysmal positional vertigo: A Turkey case-control study. Ideggyogy Sz. 2018;71:411-6. 
24. Düğeroğlu H, Kaya Y. Baş dönmesi şikayeti olan hastalarda vitamin B12 eksikliğinin değerlendirilmesi. F Üniv Sağ Bil Tıp Derg. 2018;32:123-7.

25. Ozbay I, Kahraman C, Balikci HH, Kucur C, Kahraman NK, Ozkaya DP, Oghan F. Neutrophil-to-lymphocyte ratio in patients with peripheral vertigo: a prospective controlled clinical study. Am J Otolaryngol. 2014;35:699-702.

26. Fattori B, Nacci A, Ghilardi PL, Bruschini L, Matteucci F, Ursino F. Acute peripheral vertigo: involvement of the hemostatic system. Int Tinnitus J. 2003;9:124-9
27. Hughes I, Thalmann I, Thalmann R, Ornitz DM. Mixing model systems: using zebrafish and mouse inner ear mutants and other organ systems to unravel the mystery of otoconial development. Brain Res. 2006;1091:58-74.

28. Xu Y, Zhang H, Yang H, Zhao X, Lovas S, Lundberg YW. Expression, functional, and structural analysis of proteins critical for otoconia development. Dev Dyn. 2010;239:2659-73.

29. Rhim GI. Serum vitamin D and recurrent benign paroxysmal positional vertigo. Laryngoscope Investig Otolaryngol. 2016;1:150-3. 